\title{
Adenoid Cystic Carcinoma of the Lacrimal Gland Metastasizing after a Short Follow- up to Multiple Distant Bones - a Case Report with a Review of the Literature
}

\author{
MN Haque ${ }^{1}$, ASM J Chowdhury ${ }^{2}$, MY Ali ${ }^{3}$, MMSU Islam ${ }^{4}$
}

\begin{abstract}
:
Adenoid cystic carcinoma (ACC) of the lacrimal gland is a rare disease, but it is the most common malignant epithelial tumor of the lacrimal gland, with poor prognosis. ACC of the lacrimal gland is notorious for its slow growth and tendency to recur despite surgical therapy and following radiotherapy and/or chemotherapy. This tumor type occasionally metastasize via haematogenous spread to lungs, brain and bone in decreasing order of frequency. When it happens, metastases are always multiple and wide. We report a case of a 28 -year young man followed in our Hospital with ACC of right lacrimal gland resected on April 2014 and treated with surgery followed by post-operative radiotherapy (50 Gy total dose). After one years of follow-up, Positron Emission Tomography (PET) scan reported multiple lytic lesions in distant bones specially to multiple sites of vertebral column. Fine Needle Aspiration Cytology (FNAC) confirmed metastasis of ACC. No evidence of other loco-regional or distant metastasis were described. Patient was treated with chemotherapy. After treatment, patient is actually in close follow up.
\end{abstract}

Key words: Adenoid cystic carcinoma, Lacrimal gland, Metastases, Radiotherapy.

\section{Introduction:}

Adenoid cystic carcinoma (ACC) is an uncommon malignancy that arises in secretory glands and accounts for about $1 \%$ of all head and neck malignancies ${ }^{1-3}$. ACC of the lacrimal gland is also a rare disease, but it is the most common malignant epithelial tumor of the lacrimal gland, and represents $11 \%$ of epithelial neoplasms of the lacrimal gland ${ }^{4}$ and $1.6 \%$ of all orbital tumors ${ }^{5}$. ACC was first described in literature by Theodore Billroth, and was initially named cylindroma because of its specific histopathologic characteristics ${ }^{6,7}$. The poor prognosis for patients with ACC of the lacrimal gland is well recognized ${ }^{8-10}$ and historical data $^{11}$ reported a survival rate of less than $50 \%$ at 5 years and $20 \%$ at 10 years regardless of the local treatment regimens. ACC of the lacrimal gland is

1. Dr. Md. Nizamul Haque MBBS,FCPS (Radiotherapy), M.Phil (Oncology), Associate Professor\& Head, Department of Radiotherapy, Faridpur Medical College, Faridpur.

2. Professor ASM Jahangir Chowdhury, MBBS, MS (Ortho), Professor \& Principal, Faridpur Medical College, Faridpur

3. Professor Md. Yusuf Ali MBBS, FCPS (Medicine), Professor \& Head, Department of Medicine, Faridpur Medical College, Faridpur.

4. Dr. M. M. Shahin-Ul-Islam, MBBS, FCPS (Medicine), MD (Gastroenterology), Asstt. Professor, Department of Gastroenterology, Faridpur Medical College, Faridpur.

Address of correspondence :

Dr. Md. Nizamul Haque MBBS, FCPS (Radiotherapy), M.Phil (Oncology), Associate Professor \& Head, Department of Radiotherapy, Faridpur Medical College, Faridpur.

Phone: +8801730302100, Email: haquenizamuldr@gmail.com notorious for its slow growth and tendency to recur despite surgical therapy and following radiotherapy and/or chemotherapy ${ }^{12}$. The high recurrence rate is also increased due to assumption that appropriate local therapy for ACC of the lacrimal gland remains controversial. In fact, some authors advocate conservative surgical therapy followed by externalbeam radiation therapy or proton-beam therapy, whereas others believe that radical surgery probably results in better local control and possibly better longterm survival ${ }^{12-14}$. This tumor type occasionally metastasize via haematogenous spread to lungs, brain and bone in decreasing order of frequency. When it happen, metastases are always multiple and wide ${ }^{11,14}$. There are few studies and reports on lacrimal gland ACC describing time interval to presentation of metastases and length of follow-up required ${ }^{15-17}$. We reported a case of ACC of right lacrimal gland with multiple distant metastasis in bones after one year from initial tumor. No evidence of other loco-regional or distant metastasis were described.

\section{Case Report:}

A 28-year young man with no relevant prior history presented at April 2014 to the ophthalmologist complaining of initial proptosis, swelling of the right eye and increased periorbital pressure. Ophthalmologic examination revealed apoptosis, visual acuity of $16 / 20$ in right eye (normal in contralateral one), along with 
normal pupils and color vision, minimal reduction of extraocular motility. After initial not responsive steroid therapy, orbital and cranial MRI was performed. The MRI showed a diffuse SOL involving right sub-frontal, supra \& retro-orbital region, in the region of right half of the frontal sinus and anterior to sella turcica. The lesion invade right retro-bulbar region mostly from postero-lateral and superior aspect. The lesion extending to both ethmoidal sinuses (marked in right side), shenoidal sinuses, right posterior nasopharyngeal space, right half of nasal cavity and right maxillary antrum with minimal invasion to the inferior \& lateral aspect of right frontal lobe also noted. The tumor was resected on April 2014 through bi-coronal craniotomy. On section, it showed nests of anaplastic cells arrange in cribriform pattern producing gland like spaces. Histologic report was adenoid cystic carcinoma, originated from lacrimal gland (Fig-1).

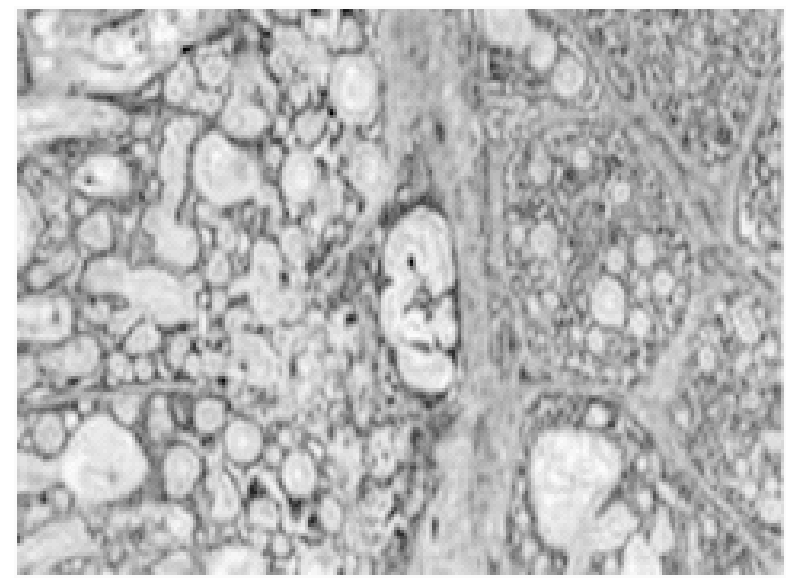

Fig-1: Histology of ACC

On these bases, Radiotherapy with 3DCRT (three dimensional conformal radiotherapy) was proposed. For this reason, on December 2014 3DCRT was performed (total dose $50 \mathrm{~Gy}$ ). Subsequent follow up was performed, without evidence of disease recurrence. From July 2015 patient complains intermittent pain in multiple sites of the body, partially responsive to nonsteroidal anti-inflammatory drugs. On August 2015 a PET scan whole body was performed, with evidence of extensive hypermetabolic bony lesions with few are osteolytic in nature seen in bilateral scapula, sternum, bilateral multiple ribs, C5, C6, C7, D1, D4, D5, D9, D11, L1, L2 and L4 vertebra, upper end of left humerous, bilateral pelvic bones, ischium, sacrum and upper end of femurs suggests multiple bony metastasis (Fig-2). No other pathologic sites are described. CT guided FNAC (Fig-3), confirmed metastasis compatible with ACC. normal pupils and color vision, minimal reduction of extraocular motility. After initial non responsive steroid therapy, orbital and cranial MRI was performed. The MRI showed a diffuse SOL involving right sub-frontal, supra \& retro-orbital region, in the region of right half of the frontal sinus and anterior to sella turcica. The lesion invade right retro-bulbar region mostly from postero-lateral and superior aspect. The lesion extending to both ethmoidal sinuses (marked in right side), shenoidal sinuses, right posterior nasopharyngeal space, right half of nasal cavity and right maxillary antrum with minimal invasion to the inferior \& lateral aspect of right frontal lobe also noted. The tumor was resected on April 2014 through bi-coronal craniotomy. On section, it showed nests of anaplastic cells arrange in cribriform pattern producing gland like spaces. Histologic report was adenoid cystic carcinoma, originated from lacrimal gland (Fig-1).

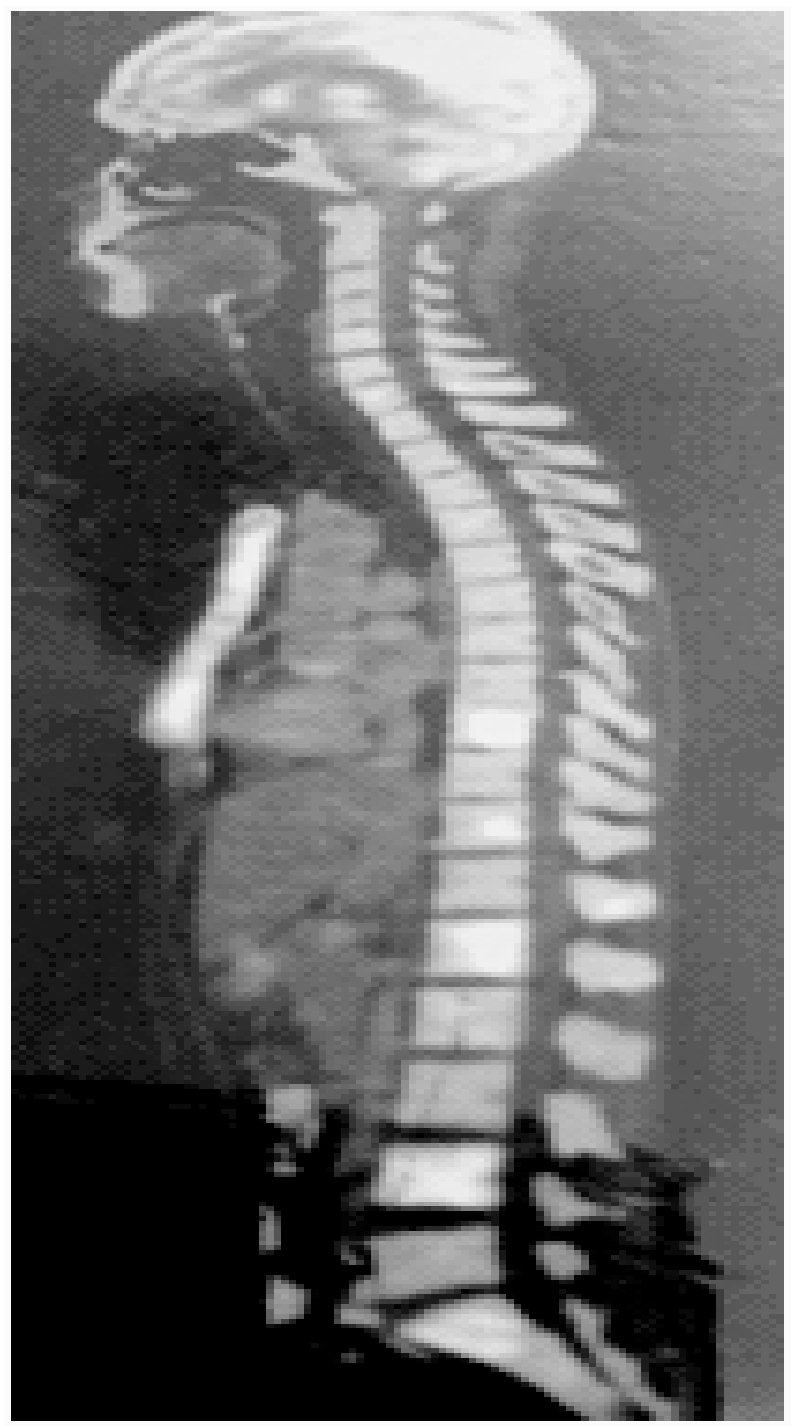

Fig-2: PET scan show vertebral metastasis. 


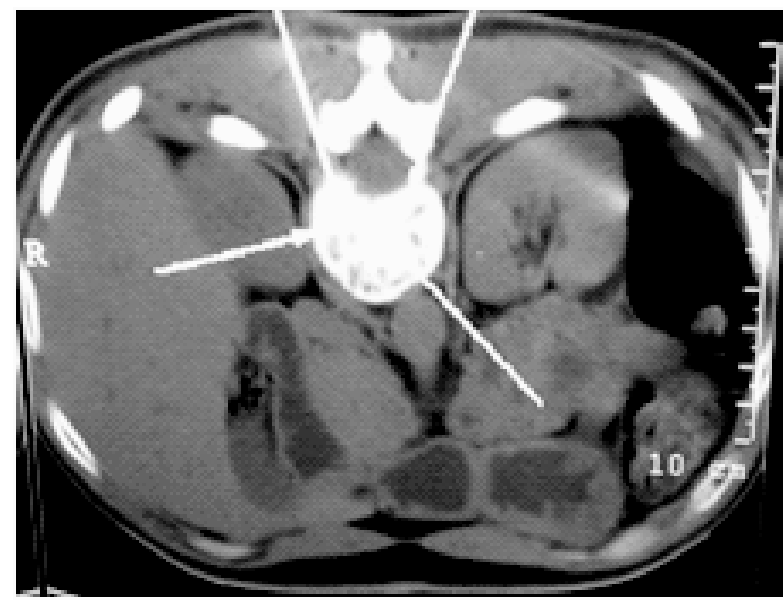

Fig-3: CT guided FNAC

The patient was treated with six cycles of chemotherapy (Inj Cisplatin \& Inj Mitoxantrone). After treatment, patient is improved clinically and is actually in close follow up.

\section{Discussion:}

The case report shows a lacrimal gland ACC in young man that recurred after one year follow up in multiple and distant bone localization. In literature, as previously explained, ACC often recurred locally and distant metastases, when present, are multiple and wide spread. Late presentation of distant metastases is a recognized feature of ACC with reported distant metastasis rates of $19-24 \%$, and a mean time to presentation of 7.6 years. Distant recurrence after 16 years has been reported, with bone and lungs as the commonest sites. Patients with lacrimal gland ACC usually at diagnosis present with a relatively short symptom duration (less than a year), and follow a painful, rapidly worsening clinical course. With regard to symptoms, pain is an important symptom of lacrimal gland and often implies perineural infiltration ${ }^{14}$. Perineural invasion is considered an indicator of poor prognosis and data showed an inherent risk of spread to local invasion and recurrence, especially to skull base ${ }^{11}$. ACC of the lacrimal gland has a greater likelihood of invading intracranially for the following reasons: more neural and vascular structures exist in the orbit; the bones of the orbit are connected directly to the intracranial cavity; and the peri-orbit and nerve sheath are closely connected. These factors increase the risk that an ACC of the lacrimal gland will invade intracranially via perineural, vascular, intraosseous, and leptomeningeal routes and via a nerve sheath ${ }^{17}$. In literature case with distal recurrence after many years are described, but always with many metastases in bone, lung and node. The difficulty in achieving a longterm disease-free survival in this disease is attributed to the complex regional orbital anatomy and the aggressive biological behavior of the tumor ${ }^{12}$. We reported the case, has similarities with the literatures that it is initially locally aggressive which is already described and has dissimilarities that it is metastases to distant sites without local recurrence after a short disease free survival. We think that this case is a special one for reporting.

\section{Conclusion:}

ACC of lacrimal gland is a rare disease. Therefore, any case of orbital abnormality should be examine and investigate carefully for early diagnosis and treatment, which is essential for better prognosis.

\section{References :}

1. Diaz EM Jr, Kies MS. Chemotherapy for skull base cancers. Otolaryngol Clin North Am 2001; 34: 1079-85.

2. Wiseman SM, Popat SR, Rigual NR, Hicks WL, Orner JB, Wein $\mathrm{RO}$, et al. Adenoid cystic carcinoma of the paranasal sinuses or nasal cavity: a 40-year review of35 cases. Ear Nose Throat J 2002; 81: $510-17$.

3. Witt RL. Adenoid cystic carcinoma of the minor salivary glands. Ear Nose Throat J 1991; 70: 218-22.

4. Rapidis AD, Givalos N, Gakiopoulou H, Faratzis G, StavrianosSD, Vilos GA, et al. Adenoid cystic carcinoma of the head and neck. Clinicopathological analysis of 23 patients and review of the literature. Oral Oncol 2005; 41: 328-35.

5. Gormley WB, Sekhar LN, Wright DC, Olding M, JaneckaIP, Snyderman $\mathrm{CH}$, et al. Management and long term outcome of adenoid cystic carcinoma with intracranial extension: A neurosurgical respective. Neurosurgery 1996; 38: 1105-13.

6. Conley J, Dingman DL. Adenoid cystic carcinoma in the head and neck (cylindroma). Arch Otolaryngol 1974; 100:81-90.

7. Lee DA, Campbell RJ, Waller RR, Ilstrup DM. A clinicopathologic study of primary adenoid cystic carcinoma of the lacrimal gland. Ophthalmology 1985; 92: 128-34.

8. Wright JE, Stewart WB, Krohel GB. Clinical presentation and management of lacrimal gland tumours. Br J Ophthalmol1979; 63: 600-06.

9. Gamel JW, Font RL. Adenoid cystic carcinoma of the lacrimal gland: the clinical significance of a basaloid histologicpattern. Hum Pathol 1982; 13: 219-25.

10. Font RL, Gamel JW. Adenoid cystic carcinoma of the lacrimal gland: a clinicopathologic study of 79 cases. In: Nicholson, DH, editor. Ocular Pathology Update. NewYork: Masson, 1980. p. 277-83.

11. Front RL, Smith SL, Bryan RG. Malignant epithelial tumors of the lacrimal gland: a clinicopathologic study of $21 \mathrm{cases}$. Arch Ophthalmol 1998; 116: 613-16.

12. Witt RL. Adenoid cystic carcinoma of the minor salivary glands. Ear Nose Throat J 1991; 70: 218-22.

13. Wright JE. Factors affecting the survival of patients with lacrimal gland tumors. Can J Ophthalmol 1982; 17: 3-9.

14. Khan AJ, DiGiovanna MP, Ross DA, Sasaki CT, CarterD, Son $\mathrm{YH}$, et al. Adenoid cystic carcinoma: A retrospective clinical review. Int J Cancer 2001; 96: 149-58.

15. Bartley GB, Harris GJ. Adenoid cystic carcinoma of the lacrimal gland: Is there a cure... yet? Ophthal Plast Reconstruct Surg 2002; 18: $315-18$.

16. Esmaeli B, Ahmadi MA, Youssef A, Diba R, Amato M,Myers JN, et al. Outcomes in patients withadenoid cystic carcinoma of the lacrimal gland. OphthalPlast Reconstruct Surg 2004; 20: 22-6.

17. Billroth T. Untersuchungenuber die Entwicklung derBluttgefasse. Berlin: Reimer, 1856. p.5-69. 